\title{
The Swiss French version of the Juvenile Arthritis Multidimensional Assessment Report (JAMAR)
}

\author{
Michael Hofer ${ }^{1,2}$ - Annette von Scheven-Gête ${ }^{1}$ Matthieu Santos ${ }^{1}$. Pierre Quartier ${ }^{3}$. Carine Wouters ${ }^{4}$. \\ Federica Vanoni $^{5} \cdot$ Rotraud K. Saurenmann $^{6}$. Alessandro Consolaro ${ }^{7,8} \cdot$ Francesca Bovis $^{7} \cdot$ Nicolino Ruperto $^{7} \cdot$ For the \\ Paediatric Rheumatology International Trials Organisation (PRINTO)
}

Received: 22 December 2017 / Accepted: 11 January 2018

(c) The Author(s) 2018. This article is an open access publication

\begin{abstract}
The Juvenile Arthritis Multidimensional Assessment Report (JAMAR) is a new parent/patient reported outcome measure that enables a thorough assessment of the disease status in children with juvenile idiopathic arthritis (JIA). We report the results of the cross-cultural adaptation and validation of the parent and patient versions of the JAMAR in the Swiss French language. The reading comprehension of the questionnaire was tested in ten JIA parents and patients. Each participating centre was asked to collect demographic, clinical data, and the JAMAR in 100 consecutive JIA patients or all consecutive patients seen in a 6-month period and to administer the JAMAR to 100 healthy children and their parents. The statistical validation phase explored descriptive statistics and the psychometric issues of the JAMAR: the three Likert assumptions, floor/ceiling effects, internal consistency, Cronbach's alpha, interscale correlations, test-retest reliability, and construct validity (convergent and discriminant validity). A total of 98 JIA patients (3.1\% systemic, $43.9 \%$ oligoarticular, $16.3 \% \mathrm{RF}$ negative polyarthritis, $36.7 \%$ other categories), and 64 healthy children were enrolled in a paediatric rheumatology centre. The JAMAR components discriminated well healthy subjects from JIA patients. All JAMAR components revealed good psychometric performances. In conclusion, the Swiss French version of the JAMAR is a valid tool for the assessment of children with JIA and is suitable for use both in routine clinical practice and clinical research.
\end{abstract}

Keywords Juvenile idiopathic arthritis $\cdot$ Disease status $\cdot$ Functional ability $\cdot$ Health-related quality of life $\cdot$ JAMAR

\section{Introduction}

The aim of the present study was to cross-culturally adapt and validate the Swiss French parent, child/adult version of the Juvenile Arthritis Multidimensional Assessment Report (JAMAR) [1] in patients with juvenile idiopathic arthritis

The local members of the Paediatric Rheumatology International TrialsOrganisation (PRINTO) participating in the project are listed in the dedicated tables no. 2 and 3 of "https://doi.org/10.1007/ s00296-018-3944-1 / Cross-cultural adaptation and psychometric evaluation of the Juvenile Arthritis Multidimensional Assessment Report (JAMAR) in 54 languages across 52 countries: review of the general methodology".

Michael Hofer michael.hofer@chuv.ch

Nicolino Ruperto nicolaruperto@gaslini.org http://www.printo.it

Extended author information available on the last page of the article
(JIA). The JAMAR assesses the most relevant parent/patient reported outcomes in JIA, including overall well-being, functional status, health-related quality of life (HRQoL), pain, morning stiffness, disease activity/status/course, articular and extra-articular involvement, drug-related side effects/compliance, and satisfaction with illness outcome.

This project was part of a larger multinational study conducted by the Paediatric Rheumatology International Trials Organisation (PRINTO) [2] aimed to evaluate the epidemiology, outcome, and treatment of childhood arthritis (EPOCA) in different geographic areas [3].

We report herein the results of the cross-cultural adaptation and validation of the parent and patient versions of the JAMAR in the Swiss French language. The Swiss German version of the JAMAR is currently under development. 


\section{Materials and methods}

The methodology employed has been described in detail in the introductory paper of the supplement [4]. In brief, it was a cross-sectional study of JIA children, classified according to the ILAR criteria [5, 6], and enrolled from June 2012 to January 2017. Children were recruited after Ethics Committee approval and consent from at least one parent.

\section{The JAMAR}

The JAMAR (1) includes the following 15 sections:

1. Assessment of physical function (PF) using 15 items in which the ability of the child to perform each task is scored as follows: $0=$ without difficulty, $1=$ with some difficulty, $2=$ with much difficulty, $3=$ unable to do and not applicable if it was not possible to answer the question or the patient was unable to perform the task due to their young age or to reasons other than JIA. The total PF score ranges from 0 to 45 and has three components: PF-lower limbs (PF-LL); PF-hand and wrist (PF-HW) and PF-upper segment (PF-US) each scoring from 0 to 15 [7]. Higher scores indicate higher degree of disability [8-10].

2. Rating of the intensity of the patient's pain on a 21-numbered circle visual analogue scale (VAS) [11].

3. Assessment of the presence of joint pain or swelling (present/absent for each joint);

4. Assessment of morning stiffness (present/absent).

5. Assessment of extra-articular symptoms (fever and rash) (present/absent).

6. Rating of the level of disease activity on a 21-circle VAS.

7. Rating of disease status at the time of the visit (categorical scale).

8. Rating of disease course from previous visit (categorical scale).

9. Checklist of the medications the patient is taking (list of choices)

10. Checklist of side effects of medications.

11. Report of difficulties with medication administration (list of items).

12. Report of school/university/work problems caused by the disease (list of items).

13. Assessment of HRQoL, through the Physical Health $(\mathrm{PhH})$, and Psychosocial Health $(\mathrm{PsH})$ subscales (5 items each) and a total score. The four-point Likert response, referring to the prior month, are 'never' (score 0 ), 'sometimes' (score 1), 'most of the time' (score 2) and 'all the time' (score 3). A 'not assessable' column was included in the parent version of the questionnaire to designate questions that cannot be answered because of developmental immaturity. The total HRQoL score ranges from 0 to 30, with higher scores indicating worse HRQoL. A separate score for $\mathrm{PhH}$ and PsH (range 0-15) can be calculated [12-14].

14. Rating of the patient's overall well-being on a 21-numbered circle VAS.

15. A question about satisfaction with the outcome of the illness (Yes/No) [15].

The JAMAR is available in three versions, one for parent proxy-report (child's age 2-18), one for child self-report, with the suggested age range of 7-18 years, and one for adults.

\section{Cross-cultural adaptation and validation}

The process of cross-cultural adaptation was conducted according to international guidelines with $2-3$ forward and backward translations. In those countries for which the translation of JAMAR had been already cross-cultural adapted in a similar language (i.e., Spanish in South American countries), only the probe technique was performed. Reading comprehension and understanding of the translated questionnaires were tested in a probe sample of ten JIA parents and ten patients.

Each participating centre was asked to collect demographic, clinical data, and the JAMAR in 100 consecutive JIA patients or all consecutive patients seen in a 6-month period and to administer the JAMAR to 100 healthy children and their parents.

The statistical validation phase explored the descriptive statistics and the psychometric issues [16]. In particular, we evaluated the following validity components: the first Likert assumption [mean and standard deviation (SD) equivalence]; the second Likert assumption or equal item-scale correlations (Pearson $r$ : all items within a scale should contribute equally to the total score); third Likert assumption (item internal consistency or linearity for which each item of a scale should be linearly related to the total score that is $90 \%$ of the items should have Pearson $r \geq 0.4$ ); floor/ceiling effects (frequency of items at lower and higher extremes of the scales, respectively); internal consistency, measured by the Cronbach's alpha, interscale correlation (the correlation between two scales should be lower than their reliability coefficients, as measured by Cronbach's alpha); test-retest reliability or intraclass correlation coefficient (reproducibility of the JAMAR repeated after 1 or 2 weeks); and construct validity in its two components: the convergent or external validity which examines the correlation of the JAMAR subscales with the six JIA core-set variables, with the addition 
of the parent assessment of disease activity and pain by the Spearman's correlation coefficients $(r)$ [17] and the discriminant validity, which assesses whether the JAMAR discriminates between the different JIA categories and healthy children [18]. Quantitative data were reported as medians with first and third quartiles and categorical data as absolute frequencies and percentages.

The complete Swiss French parent and patient versions of the JAMAR are available upon request to PRINTO.

\section{Results}

\section{Cross-cultural adaptation}

The Swiss French JAMAR was fully cross-culturally adapted from the standard English version with three forward and two backward translations with a concordance for 121/123 (98.4\%) translations lines for the parent version and 118/120 (98.3\%) lines for the child version.

All 123 lines of the parent version of the JAMAR were understood by at least $80 \%$ of the ten parents tested (median $100 \%$; range $80-100 \%$ ). All the 120 lines of the patient version of the JAMAR were understood by at least $80 \%$ of the children (median 100\%; range 80-100\%). The parent and child versions of the Swiss French JAMAR were unmodified after the probe technique.

\section{Demographic and clinical characteristics of the subjects}

A total of 100 JIA patients and 67 healthy children (total of 167 subjects) were enrolled at the paediatric rheumatology centre of Lausanne. Two patients and three healthy children did not give the consent to use their data.

In the remaining 98 JIA subjects, the JIA categories were $3.1 \%$ with systemic arthritis, $43.9 \%$ with oligoarthritis, $16.3 \%$ with RF negative polyarthritis, $2 \%$ with psoriatic arthritis, $25.5 \%$ with enthesitis-related arthritis, and $9.2 \%$ with undifferentiated arthritis. Notably, none of the enrolled JIA patients is affected with RF positive polyarthritis (Table 1).

A total of 154/162 (95.1\%) subjects had the parent version of the JAMAR completed by a parent ( 96 from parents of JIA patients and 58 from parents of healthy children). The JAMAR was completed by $132 / 154(85.7 \%)$ mothers and $22 / 154(14.3 \%)$ fathers. The child version of the JAMAR was completed by $102 / 162(63 \%)$ children age 6.4 or older. In addition, patients younger than 7 years old, capable to assess their personal condition and able to read and write, were asked to fill in the patient version of the questionnaire.

\section{Discriminant validity}

The JAMAR results are presented in Table 1, including the scores [median (1st-3rd quartile)] obtained for the PF, the $\mathrm{PhH}$, the PsH subscales, and total score of the HRQoL scales. The JAMAR components discriminated well between healthy subjects and JIA patients. In summary, the JAMAR revealed that JIA patients had a greater level of disability and pain, as well as a lower HRQoL than their healthy peers.

\section{Psychometric issues}

The main psychometric properties of both parent and child versions of the JAMAR are reported in Table 2. The following "Results" section refers mainly to the parent's version findings, unless otherwise specified.

\section{Descriptive statistics (first Likert assumption)}

There were no missing results for all JAMAR items, since data were collected through a Web-based system that did not allow to skip answers and input of null values. The response pattern for both PF and HRQoL was positively skewed toward normal functional ability and normal HRQoL. All response choices were used for the different HRQoL items 4,6 , and 8 , whereas a reduced number of response choices were used for all the PF items.

The mean and SD of the items within a scale were roughly equivalent for the PF and for the HRQoL items, except for HRQoL item 5 (data not shown). The median number of items marked as not applicable was $0 \%(0-1 \%)$ for the PF and 2\% (1-3\%) for the HRQoL.

\section{Floor and ceiling effect}

The median floor effect was $87.5 \%(82.3-91.7 \%)$ for the PF items, 63.5\% (51.0-66.7\%) for the HRQoL PhH items, and $60.4 \%$ (59.4-61.5\%) for the HRQoL PsH items. The median ceiling effect was $0 \%(0-0 \%)$ for the PF items, $5.2 \%$ (2.1-5.2\%) for the HRQoL PhH items, and $2.1 \%(0-2.1 \%)$ for the HRQoL PsH items. The median floor effect was $37.5 \%$ for the pain VAS, $35.4 \%$ for the disease activity VAS, and $35.4 \%$ for the well-being VAS. The median ceiling effect was $1.0 \%$ for the pain VAS, $2.1 \%$ for the disease activity VAS, and $1.0 \%$ for the well-being VAS.

\section{Equal item-scale correlations (second Likert assumption)}

Pearson item-scale correlations corrected for overlap were roughly equivalent for items within a scale for $80 \%$ of the PF 
Table 1 Descriptive statistics (medians, first-third quartiles or absolute frequencies, and \%) for the 98 JIA patients

\begin{tabular}{|c|c|c|c|c|c|c|c|c|}
\hline & Systemic, $N=3$ & $\begin{array}{l}\text { Oligoarthritis, } \\
\mathrm{N}=43\end{array}$ & $\begin{array}{l}\text { RF-polyarthri- } \\
\text { tis, } N=16\end{array}$ & $\begin{array}{l}\text { Psoriatic arthri- } \\
\text { tis, } N=2\end{array}$ & $\begin{array}{l}\text { Enthesitis- } \\
\text { related arthritis, } \\
\mathrm{N}=25\end{array}$ & $\begin{array}{l}\text { Undifferenti- } \\
\text { ated arthritis, } \\
N=9\end{array}$ & $\begin{array}{l}\text { All JIA } \\
\text { patients, } N=98\end{array}$ & Healthy, $N=64$ \\
\hline Female & $3(100 \%)$ & $32(74.4 \%)$ & $14(87.5 \%)$ & $2(100 \%)$ & $14(56 \%)$ & $5(55.6 \%)$ & $70(71.4 \%)$ & $32(50 \%)^{*}$ \\
\hline Age at visit & $\begin{array}{l}15.5(11.5- \\
19.8)\end{array}$ & $9.5(6.8-11.7)$ & $15.8(8.4-17.6)$ & $\begin{array}{l}15.1(13.6- \\
16.5)\end{array}$ & $\begin{array}{l}15.4(11.7- \\
16.8)\end{array}$ & $11.1(4.8-14.3)$ & $\begin{array}{c}11.6(7.7- \\
16.3)^{*}\end{array}$ & $8.4(4.7-14.5)^{*}$ \\
\hline Age at onset & $11(8.1-14.2)$ & $3.1(1.8-6.6)$ & $7.3(2.2-10.9)$ & $\begin{array}{l}11.5(11.4- \\
11.7)\end{array}$ & $10(8.7-12.6)$ & $5(1.8-9)$ & $6.8(2.5-10.4)^{\#}$ & \\
\hline Disease duration & $5.6(0.6-7.3)$ & $4.1(2.3-8.3)$ & $4.4(2.9-9.8)$ & $3.5(1.9-5.2)$ & $3.3(2.2-5.4)$ & $2.2(1.7-6.1)$ & $3.9(2.2-7.3)$ & \\
\hline ESR & $45(11-70)$ & $9.5(7-16)$ & $10(7-17)$ & $2(2-2)$ & $7.5(5.5-15.5)$ & $9.5(6-22)$ & $10(6-17)$ & \\
\hline $\begin{array}{l}\text { MD VAS } \\
\qquad(0-10 \mathrm{~cm})\end{array}$ & $1(0-5)$ & $0(0-1)$ & $0.8(0-4)$ & $0.8(0-1.5)$ & $2(1-3)$ & $0(0-1)$ & $0.5(0-2)^{*}$ & \\
\hline No. swollen joints & $0(0-0)$ & $0(0-1)$ & $0(0-0)$ & $5.5(0-11)$ & $0(0-0)$ & $0(0-1)$ & $0(0-0)$ & \\
\hline $\begin{array}{l}\text { No. joints with } \\
\text { pain }\end{array}$ & $0(0-0)$ & $0(0-1)$ & $0.5(0-4.5)$ & $1(1-1)$ & $3(1-7)$ & $0(0-1)$ & $0.5(0-3) * *$ & \\
\hline $\begin{array}{l}\text { No. joints with } \\
\text { LOM }\end{array}$ & $0(0-1)$ & $0(0-1)$ & $0(0-0.5)$ & $2(1-3)$ & $0(0-0)$ & $0(0-0)$ & $0(0-1)$ & \\
\hline No. active joints & $0(0-0)$ & $0(0-1)$ & $0(0-0.5)$ & $6(1-11)$ & $0(0-0)$ & $0(0-1)$ & $0(0-1)$ & \\
\hline $\begin{array}{l}\text { Active systemic } \\
\text { features }\end{array}$ & $0(0 \%)$ & $0(0 \%)$ & $0(0 \%)$ & $0(0 \%)$ & $2(8 \%)$ & $0(0 \%)$ & $2(2 \%)$ & \\
\hline ANA status & $0(0 \%)$ & $5(11.6 \%)$ & $3(18.8 \%)$ & $0(0 \%)$ & $2(8 \%)$ & $2(22.2 \%)$ & $12(12.2 \%)$ & \\
\hline Uveitis & $0(0 \%)$ & $6(14 \%)$ & $1(6.3 \%)$ & $0(0 \%)$ & $1(4 \%)$ & $0(0 \%)$ & $8(8.2 \%)$ & \\
\hline PF total score & $0(0-1)$ & $0(0-3)$ & $1(0-6)$ & $0.5(0-1)$ & $3(1-4)$ & $1(0-3)$ & $1(0-3)$ & $0(0-0)^{* *}$ \\
\hline Pain VAS & $2(0.5-3.5)$ & $0.5(0-5)$ & $1.5(0-2.8)$ & $0.5(0-1)$ & $3(1.5-8)$ & $0(0-3.5)$ & $1.8(0-4.5)$ & $0(0-0)^{\#}$ \\
\hline $\begin{array}{l}\text { Disease activity } \\
\text { VAS }\end{array}$ & $0.5(0-2.5)$ & $1(0-4.5)$ & $2(0-4.8)$ & $0.5(0-1)$ & $3(1-5.5)$ & $0.5(0-3.5)$ & $1.8(0-4.5)$ & \\
\hline Well-being VAS & $0.5(0-1)$ & $0.5(0-3)$ & $2.8(0.3-4.5)$ & $0.3(0-0.5)$ & $2.5(1.5-5.5)$ & $0(0-2)$ & $1.3(0-4)^{*}$ & \\
\hline HRQoL PhH & $4(0-99)$ & $1(0-4)$ & $3(1-7)$ & $1.5(0-3)$ & $2(2-4)$ & $1(0-5)$ & $2(0-4)$ & $0(0-1)^{\#}$ \\
\hline HRQoL PsH & $99(0-99)$ & $1(0-3)$ & $2(1-6)$ & $0.5(0-1)$ & $1(0-4)$ & $1(0-3)$ & $1(0-4)$ & $0(0-2)^{*}$ \\
\hline $\begin{array}{l}\text { HRQoL total } \\
\text { score }\end{array}$ & $99(0-99)$ & $2(0-8)$ & $6.5(2.5-12)$ & $2(1-3)$ & $4(2-9)$ & $5(0-10)$ & $4(1-9)$ & $0(0-4)^{* * *}$ \\
\hline $\begin{array}{l}\text { Pain/swell. in }>1 \\
\text { joint }\end{array}$ & $2(66.7 \%)$ & $23(53.5 \%)$ & $10(62.5 \%)$ & $2(100 \%)$ & $22 / 23(95.7 \%)$ & $4(44.4 \%)$ & $63 / 96(65.6 \%)$ & $5 / 58(8.6 \%)^{*}$ \\
\hline $\begin{array}{l}\text { Morning stiff- } \\
\text { ness }>15 \text { min }\end{array}$ & $0(0 \%)$ & $8(18.6 \%)$ & $2(12.5 \%)$ & $0(0 \%)$ & $7 / 23(30.4 \%)$ & $0(0 \%)$ & $17 / 96(17.7 \%)$ & $2 / 58(3.4 \%)^{*}$ \\
\hline $\begin{array}{l}\text { Subjective remis- } \\
\text { sion }\end{array}$ & $1(33.3 \%)$ & $23(53.5 \%)$ & $10(62.5 \%)$ & $1(50 \%)$ & $20 / 23(87 \%)$ & $2(22.2 \%)$ & $57 / 96(59.4 \%)$ & \\
\hline In treatment & $3(100 \%)$ & $17(39.5 \%)$ & $16(100 \%)$ & $0(0 \%)$ & $19 / 23(82.6 \%)$ & $6(66.7 \%)$ & $61 / 96(63.5 \%)$ & \\
\hline $\begin{array}{l}\text { Reporting side } \\
\text { effects }\end{array}$ & $0(0 \%)$ & 3/17 (17.6\%) & $5(31.3 \%)$ & $0(0 \%)$ & $5 / 19(26.3 \%)$ & $2 / 6(33.3 \%)$ & $15 / 61(24.6 \%)$ & \\
\hline $\begin{array}{l}\text { Taking medica- } \\
\text { tion regularly }\end{array}$ & $3(100 \%)$ & $16 / 17(94.1 \%)$ & $15(93.8 \%)$ & $0(0 \%)$ & 19/19 (100\%) & $6 / 6(100 \%)$ & $59 / 61(96.7 \%)$ & \\
\hline $\begin{array}{l}\text { With problems } \\
\text { attending } \\
\text { school }\end{array}$ & $0(0 \%)$ & $2 / 27(7.4 \%)$ & $3 / 12(25 \%)$ & $0(0 \%)$ & $4 / 15(26.7 \%)$ & $1 / 5(20 \%)$ & $10 / 61(16.4 \%)$ & $0(0 \%)^{*}$ \\
\hline $\begin{array}{l}\text { Satisfied with dis- } \\
\text { ease outcome }\end{array}$ & $2(66.7 \%)$ & $29(67.4 \%)$ & $11(68.8 \%)$ & $2(100 \%)$ & $14 / 23(60.9 \%)$ & $8(88.9 \%)$ & 66/96 (68.8\%) & \\
\hline
\end{tabular}

Data related to the JAMAR refer to the 96 JIA patients and to the 58 healthy subjects for whom the questionnaire has been completed by the parents

JAMAR Juvenile Arthritis Multidimensional Assessment Report, ESR erythrocyte sedimentation rate, MD medical doctor, VAS visual analogue scale (score $0-10 ; 0=$ no activity, $10=$ maximum activity), LOM limitation of motion, ANA anti-nuclear antibodies, $P F$ physical function (total score ranges from 0 to 45), $H R Q o L$ health-related quality of life (total score ranges from 0 to 30), $P h H$ physical health (total score ranges from 0 to 15$), P s H$ psychosocial health (total score ranges from 0 to 15 )

$p$ values refer to the comparison of the different JIA categories or to JIA versus healthy. ${ }^{*} p<0.05,{ }^{* *} p<0.001,{ }^{\#} p<0.0001$ 
Table 2 Main psychometric characteristics between the parent and child version of the JAMAR

\begin{tabular}{|c|c|c|}
\hline & Parent, $N=96 / 154$ & Child, $N=78 / 102$ \\
\hline Missing values (first-third quartiles) & No missing values & No missing values \\
\hline Response pattern & PF and HRQoL positively skewed & PF and HRQoL positively skewed \\
\hline \multicolumn{3}{|l|}{ Floor effect, median } \\
\hline $\mathrm{PF}$ & $87.5 \%$ & $84.6 \%$ \\
\hline HRQoL PhH & $63.5 \%$ & $57.7 \%$ \\
\hline HRQoL PsH & $60.4 \%$ & $61.5 \%$ \\
\hline Pain VAS & $37.5 \%$ & $26.9 \%$ \\
\hline Disease activity VAS & $35.4 \%$ & $29.5 \%$ \\
\hline Well-being VAS & $35.4 \%$ & $33.3 \%$ \\
\hline \multicolumn{3}{|l|}{ Ceiling effect, median } \\
\hline PF & $0.0 \%$ & $0.0 \%$ \\
\hline HRQoL PhH & $5.2 \%$ & $2.6 \%$ \\
\hline HRQoL PsH & $2.1 \%$ & $1.3 \%$ \\
\hline Pain VAS & $1.0 \%$ & $2.6 \%$ \\
\hline Disease activity VAS & $2.1 \%$ & $1.3 \%$ \\
\hline Well-being VAS & $1.0 \%$ & $1.3 \%$ \\
\hline Items with equivalent item-scale correlation & $80 \%$ for $\mathrm{PF}, 90 \%$ for $\mathrm{HRQoL}$ & $87 \%$ for PF, $100 \%$ for $\mathrm{HRQoL}$ \\
\hline Items with item-scale correlation $\geq 0.4$ & $73 \%$ for $\mathrm{PF}, 100 \%$ for $\mathrm{HRQoL}$ & $87 \%$ for $\mathrm{PF}, 90 \%$ for $\mathrm{HRQoL}$ \\
\hline \multicolumn{3}{|l|}{ Cronbach's alpha } \\
\hline PF-LL & 0.75 & 0.73 \\
\hline PF-HW & 0.83 & 0.79 \\
\hline PF-US & 0.68 & 0.75 \\
\hline HRQoL PhH & 0.85 & 0.86 \\
\hline HRQoL PsH & 0.78 & 0.76 \\
\hline Items with item-scale correlation lower than the Cronbach alpha & $100 \%$ for $\mathrm{PF}, 100 \%$ for $\mathrm{HRQoL}$ & $100 \%$ for PF, $100 \%$ for $\mathrm{HRQoL}$ \\
\hline \multicolumn{3}{|l|}{ Test-retest intraclass correlation } \\
\hline PF total score & 0.79 & 0.78 \\
\hline HRQoL PhH & 0.87 & 0.84 \\
\hline HRQoL PsH & 0.00 & 0.29 \\
\hline \multicolumn{3}{|l|}{ Spearman correlation with JIA core-set variables, median } \\
\hline $\mathrm{PF}$ & 0.5 & 0.5 \\
\hline HRQoL PhH & 0.6 & 0.6 \\
\hline HRQoL PsH & 0.4 & 0.4 \\
\hline Pain VAS & 0.1 & 0.1 \\
\hline Disease activity VAS & 0.1 & 0.1 \\
\hline Well-being VAS & 0.1 & 0.1 \\
\hline
\end{tabular}

JAMAR Juvenile Arthritis Multidimensional Assessment Report, JIA juvenile idiopathic arthritis, VAS visual analogue scale, $P F$ physical function, $H R Q o L$ health-related quality of life, $P h H$ physical health, $P s H$ psychosocial health, $P F-L L$ PF-lower limbs, $P F-H W$ PF-hand and wrist, PF-US PF-upper segment

items, with the exception of items 5, 11, and 12, and for $90 \%$ of the HRQoL items, with the exception of item 1.

\section{Items internal consistency (third Likert assumption)}

Pearson item-scale correlations were $\geq 0.4$ for $73 \%$ of items of the PF (except for PF items 5, 13, 14, and 15) and $100 \%$ of items of the HRQoL.

\section{Cronbach's alpha internal consistency}

Cronbach's alpha was 0.75 for PF-LL, 0.83 for PF-HW, and 0.68 for PF-US. Cronbach's alpha was 0.85 for HRQoL $\mathrm{PhH}$ and 0.78 for HRQoL PsH. 


\section{Interscale correlation}

The Pearson correlation of each item of the PF and the HRQoL with all items included in the remaining scales of the questionnaires was lower than the Cronbach's alpha.

\section{Test-retest reliability}

Reliability was assessed in nine JIA patients, by re-administering both versions (parent and child) of the JAMAR after a median of 15 days (range 12-16 days). The intraclass correlation coefficients (ICC) for the PF total score showed a substantial reproducibility (ICC 0.79). The ICC for the HRQoL PhH showed an almost perfect reproducibility (ICC 0.87) and the ICC for the HRQoL PsH showed a poor reproducibility (ICC 0.0 ).

\section{Convergent validity}

The Spearman correlation of the PF total score with the JIA core set of outcome variables ranged from 0.1 to 0.6 (median 0.5 ). The PF total score best correlation was observed with the parent assessment of well-being $(r=0.61, p<0.001)$. For the HRQoL, the median correlation of the $\mathrm{PhH}$ with the JIA core set of outcome variables ranged from 0.1 to 0.7 (median 0.6 ), whereas that for the PsH ranged from 0.1 to 0.6 (median 0.4). The $\mathrm{PhH}$ showed the best correlation with the parent's assessment of pain $(r=0.74, p<0.001)$ and the PsH with the parent's assessment of pain $(r=0.71, p<0.001)$. The median correlations between the pain VAS, the well-being VAS, and the disease activity VAS and the physician-centred and laboratory measures were $0.1(0.1-0.3), 0.1(0.02-0.3)$, and $0.1(0.1-0.3)$, respectively.

\section{Discussion}

In this study, the Swiss French version of the JAMAR was cross-culturally adapted from the standard English version with three forward and two backward translations. According to the results of the validation analysis, the Swiss French parent and patient versions of the JAMAR possess satisfactory psychometric properties. The disease-specific components of the questionnaire discriminated well between patients with JIA and healthy controls.

Psychometric performances were good for all domains of the JAMAR with a few exceptions: four PF items ("Bend down to pick up an object off the floor", "Turn head and look over shoulders", "Bend head back and look at the ceiling", and "Bite into a sandwich or an apple") showed a lower items internal consistency. However, the overall internal consistency was at least acceptable for all the domains (except for PF-US that is questionable).

In the external validity evaluation, the Spearman's correlations of the PF and HRQoL scores with JIA core-set parameters ranged from weak to strong.

The statistical performances of the child version of the JAMAR are very similar, although even better, to those obtained by the parent version, which suggests that children are reliable reporters of their disease and health status.

The JAMAR is aimed to evaluate the side effects of medications and school attendance, which are other dimensions of daily life that were not previously considered by other HRQoL tools. This may provide useful information for intervention and follow-up in health care. In conclusion, the Swiss French version of the JAMAR was found to have satisfactory psychometric properties; and it is, thus, a reliable and valid tool for the multidimensional assessment of children with JIA.

Acknowledgements We thank all families who participated in the project, the team that prepared and reviewed the forward and backward translations, and all members of PRINTO in Switzerland. We thank the staff of the PRINTO International Coordinating Centre in Genoa (Italy) and in particular Marco Garrone for the overall coordination of the translation process, Silvia Scala and Elisa Patrone for data collection and quality assurance, Luca Villa, Giuseppe Silvestri and Mariangela Rinaldi for the database development and management and the remaining PRINTO team for data entry. The Principal Investigator of the study was Prof. Angelo Ravelli, MD. The scientific coordinator and study methodologist was Nicolino Ruperto, MD, MPH. The project coordinators were Alessandro Consolaro, MD, PhD, Francesca Bovis, PhD. We thank also Prof. Alberto Martini, PRINTO Chairman. Funding was provided by the Istituto G. Gaslini, Genoa (Italy). Permission for use of JAMAR and its translations must be obtained in writing from PRINTO, Genoa, Italy. All JAMAR-related inquiries should be directed to at printo@gaslini.org. Permission for use of CHAQ and CHQ derived-material is granted through the scientific cooperation of the copyright holder ICORE of Woodside CA and HealthActCHQ Inc. of Boston, Massachusetts USA. All CHQ-related inquiries should be directed to licensing@healthactchq.com. All CHAQ-related inquiries should be directed to gsingh@ @stanford.edu.

Funding This study was funded and coordinated by Istituto Giannina Gaslini, Genoa, Italy.

Conflict of interest Dr. Ruperto has received grants from BMS, Hoffman-La Roche, Janssen, Novartis, Pfizer, Sobi, during the conduct of the study and personal fees and speaker honorarium from Abbvie, Ablynx, Amgen, AstraZeneca, Baxalta Biosimilars, Biogen Idec, Boehringer, Bristol Myers Squibb, Celgene, Eli-Lilly, EMD Serono, Gilead Sciences, Janssen, Medimmune, Novartis, Pfizer, Rpharm, Roche, Sanofi, Servier and Takeda. Prof. Hofer, Dr von Scheven-Gête and Dr Santos report funding support from Istituto Giannina Gaslini, Genoa, Italy, for the translation and data collection performed at their sites within the EPOCA project. Dr. Consolaro, Dr. Bovis, Dr Quartier, Dr Wouters, Dr Vanoni, and Dr Saurenmann have nothing to disclose. 
Ethical approval All procedures performed in studies involving human participants were in accordance with the ethical standards of the institutional and/or national research committee and with the 1964 Helsinki Declaration and its later amendments or comparable ethical standards.

Informed consent Informed consent was obtained from all individual participants included in the study as per the requirement of the local ethical committee.

Open Access This article is distributed under the terms of the Creative Commons Attribution 4.0 International License (http://creativeco mmons.org/licenses/by/4.0/), which permits unrestricted use, distribution, and reproduction in any medium, provided you give appropriate credit to the original author(s) and the source, provide a link to the Creative Commons license, and indicate if changes were made.

\section{References}

1. Filocamo G, Consolaro A, Schiappapietra B, Dalpra S, Lattanzi B, Magni-Manzoni S et al (2011) A new approach to clinical care of juvenile idiopathic arthritis: the Juvenile Arthritis Multidimensional Assessment Report. J Rheumatol 38(5):938-953

2. Ruperto N, Martini A (2011) Networking in paediatrics: the example of the Paediatric Rheumatology International Trials Organisation (PRINTO). Arch Dis Child 96(6):596-601

3. Consolaro A, Ruperto N, Filocamo G, Lanni S, Bracciolini G, Garrone M et al (2012) Seeking insights into the epidemiology, treatment and outcome of childhood arthritis through a multinational collaborative effort: introduction of the EPOCA study. Pediatr Rheumatol Online J 10(1):39

4. Bovis F, Consolaro A, Pistorio A, Garrone M, Scala S, Patrone E et al (2018) Cross-cultural adaptation and psychometric evaluation of the Juvenile Arthritis Multidimensional Assessment Report (JAMAR) in 54 languages across 52 countries: review of the general methodology. Rheumatol Int. https://doi.org/10.1007/ s00296-018-3944-1 (in this issue)

5. Petty RE, Southwood TR, Baum J, Bhettay E, Glass DN, Manners P et al (1998) Revision of the proposed classification criteria for juvenile idiopathic arthritis: Durban, 1997. J Rheumatol 25(10):1991-1994

6. Petty RE, Southwood TR, Manners P, Baum J, Glass DN, Goldenberg $J$ et al (2004) International League of Associations for Rheumatology classification of juvenile idiopathic arthritis: second revision, Edmonton, 2001. J Rheumatol 31(2):390-392
7. Filocamo G, Sztajnbok F, Cespedes-Cruz A, Magni-Manzoni S, Pistorio A, Viola S et al (2007) Development and validation of a new short and simple measure of physical function for juvenile idiopathic arthritis. Arthritis Rheum 57(6):913-20

8. Lovell DJ, Howe S, Shear E, Hartner S, McGirr G, Schulte M et al (1989) Development of a disability measurement tool for juvenile rheumatoid arthritis. The juvenile arthritis functional assessment scale. Arthritis Rheum 32:1390-1395

9. Howe S, Levinson J, Shear E, Hartner S, McGirr G, Schulte M et al (1991) Development of a disability measurement tool for juvenile rheumatoid arthritis. The juvenile arthritis functional assessment report for children and their parents. Arthritis Rheum 34:873-80

10. Singh G, Athreya BH, Fries JF, Goldsmith DP (1994) Measurement of health status in children with juvenile rheumatoid arthritis. Arthritis Rheum 37:1761-1769

11. Filocamo G, Davi S, Pistorio A, Bertamino M, Ruperto N, Lattanzi B et al (2010) Evaluation of 21-numbered circle and 10-centimeter horizontal line visual analog scales for physician and parent subjective ratings in juvenile idiopathic arthritis. J Rheumatol 37(7):1534-1541

12. Duffy CM, Arsenault L, Duffy KN, Paquin JD, Strawczynski H (1997) The juvenile arthritis quality of life questionnaire-development of a new responsive index for juvenile rheumatoid arthritis and juvenile spondyloarthritides. J Rheumatol 24(4):738-46

13. Varni JW, Seid M, Knight TS, Burwinkle T, Brown J, Szer IS (2002) The PedsQL(TM) in pediatric rheumatology—reliability, validity, and responsiveness of the Pediatric Quality of Life Inventory(TM) generic core scales and rheumatology module. Arthritis Rheum 46(3):714-25

14. Landgraf JM, Abetz L, Ware JE (1996) The CHQ user's manual. 1 st edn. The Health Institute, New England Medical Center, Boston

15. Filocamo G, Consolaro A, Schiappapietra B, Ruperto N, Pistorio A, Solari N et al (2012) Parent and child acceptable symptom state in juvenile idiopathic arthritis. J Rheumatol 39(4):856-63

16. Nunnally JC (1978) Psychometric theory, 2nd edn. McGraw-Hill, New York

17. Giannini EH, Ruperto N, Ravelli A, Lovell DJ, Felson DT, Martini A (1997) Preliminary definition of improvement in juvenile arthritis. Arthritis Rheum 40(7):1202-1209

18. Ware JE Jr, Harris WJ, Gandek B, Rogers BW, Reese PR (1997) MAP-R for Windows: Multitrait/multi-item analysis programrevised user's guide. Version 1.0 ed. Health Assessment Lab, Boston

\section{Affiliations}

\section{Michael Hofer ${ }^{1,2}$. Annette von Scheven-Gête ${ }^{1} \cdot$ Matthieu Santos $^{1} \cdot$ Pierre Quartier $^{3}$. Carine Wouters ${ }^{4}$. Federica Vanoni ${ }^{5} \cdot$ Rotraud K. Saurenmann $^{6} \cdot$ Alessandro Consolaro $^{7,8} \cdot$ Francesca Bovis $^{7} \cdot$ Nicolino Ruperto $^{7} \cdot$ For the Paediatric Rheumatology International Trials Organisation (PRINTO)}

Annette von Scheven-Gête

annette.von-scheven@chuv.ch

Matthieu Santos

matthieu.santos@chuv.ch

Pierre Quartier

pierre.quartier@aphp.fr

Carine Wouters

carine.wouters@uzleuven.be
Federica Vanoni

federica.vanoni@eoc.ch

Rotraud K. Saurenmann

Traudel.Saurenmann@ksw.ch

Alessandro Consolaro

alessandroconsolaro@gaslini.org

Francesca Bovis

francescabovis@gaslini.org 
1 Unité Romande d'Immuno-Rhumatologie Pediatrique, CHUV, University of Lausanne, Lausanne, Switzerland

2 Unité Romande d'Immuno-Rhumatologie Pediatrique, University of Geneva, Geneva, Switzerland

3 Université Paris-Descartes, Institut IMAGINE, Centre de Référence National Pour les Rhumatismes Inflammatoires et les Maladies Auto-Immunes Systémiques Rares de l'Enfant (RAISE), Unité d'Immunologie, Hématologie et Rhumatologie Pédiatrique, Hôpital Necker-Enfants Malades, Assistance Publique Hôpitaux de Paris, Paris, France

4 UZ Leuven-Universitair Ziekenhuis, Reumatologie-Campus Gasthuisberg, Leuven, Belgium
5 Dipartimento di Pediatria, Ospedale Regionale di Bellinzona e Valli, Bellinzona, Switzerland

6 Kantonsspital Winterthur, Pediatric and Adolescent Medicine, Winterthur, Switzerland

7 Clinica Pediatrica e Reumatologia, Paediatric Rheumatology International Trials Organisation (PRINTO), Istituto Giannina Gaslini, Via Gaslini, 5, 16147 Genoa, Italy

8 Dipartimento di Pediatria, Università di Genova, Genoa, Italy 